\title{
Penetration of naproxen and salicylate into inflammatory exudates in the rat
}

\author{
NIALl S. DOHERTY, MARKKU ANTTILA, AND PETER B. DEAN* \\ From Lääke-Medipolar Research Centre, Turku, Finland, and the Department of Radiology, University \\ Central Hospital, Turku, Finland*
}

SUMMARY Acute inflammation was induced in rats by subcutaneous implantation of plastic sponges, and the penetration of salicylate and naproxen into the inflammatory exudate was studied ${ }_{\omega}^{\circ}$ after oral dosing with these compounds. The penetration of intravenously administered ${ }^{22} \mathrm{Na}$ and ${ }_{\omega}^{\circ}$ ${ }^{125}$ I-albumin was also studied. It was found that salicylate and ${ }^{22} \mathrm{Na}$ penetrated very rapidly, reaching ${ }_{\mathrm{N}}$ maximum concentration in the exudate within 3 hours of administration. In contrast, naproxen and $\overrightarrow{+}$ ${ }^{125} \mathrm{I}$-albumin penetrated much more slowly, maximum concentrations in the exudates not being의 reached until 5 hours after administration. The significance of these results and the role of protein binding is discussed.

It is generally assumed that it is only the unbound or 'free' fraction of drug in the blood stream which can leave the vasculature, reach the site of action, and exert a pharmacological effect (Gillette, 1973; Koch-Weser and Sellers, 1976). Some acidic antiinflammatory agents exhibit such a high degree of protein binding that in some cases less than $1 \%$ of the total drug in plasma is free. However, during inflammation the vasculature becomes much more permeable to proteins (Williams and Morley, 1974) and presumably also to drug-protein complexes. It therefore seemed of interest to compare the rates at which an extensively protein-bound acidic antiinflammatory agent, naproxen, and a less extensively bound acidic anti-inflammatory agent, salicylate, entered an inflammatory lesion. Naproxen represents the upper limit of protein binding found with acidic anti-inflammatory agents and salicylate the lower limit. The penetration of ${ }^{125} \mathrm{I}$-labelled albumin and ${ }^{22} \mathrm{Na}^{+}$were also compared. The acute inflammation induced by subcutaneous implantation of plastic sponges into rats was used as a model system.

\section{Materials and methods}

Naproxen $[(+)$ - 6 - methoxy - $\alpha$ - methyl - 2 napthaleneaceticacid] was a gift from Syntex Research, Palo Alto, California, USA. Sodium salicylate was purchased from E. Merck, Darmstadt, FRG.

Accepted for publication July 15, 1976

Correspondence to Dr. N. Doherty, Roche Products Ltd., PO Box 8, Welwyn Garden City, Herts. AL7 3AY.
Female Sprague-Dawley rats weighing between 140 and $180 \mathrm{~g}$ were used. They were maintained on a standard laboratory diet and tap water. Drugso were administered orally, naproxen $(10 \mathrm{mg} / \mathrm{kg}) \leq$ suspended in $1 \%$ carboxymethyl cellulose, sodium salicylate $(200 \mathrm{mg} / \mathrm{kg})$ dissolved in water $(1 \mathrm{ml} \%$ vehicle/100 $\mathrm{g}$ body weight).

The rats were lightly anaesthetized with ether and $\overrightarrow{\vec{O}}$ two plastic sponges $(1 \times 1 \times 0.5 \mathrm{~cm})$ were implanted $\exists$ subcutaneously into each animal as described by Ford-Hutchinson et al (1975). At various times aftero implantation groups of animals were killed and blood@ samples taken into dry plastic tubes containing EDTA (1 mg neutralized EDTA per $\mathrm{ml}$ blood). The sponges were removed and the inflammatory exudate expressed into tubes containing EDTA. The tubes were centrifuged $(2000 \mathrm{~g} \times 10 \mathrm{~min})$ at room temperature and the plasma- and cell-free inflammatory exudates used for analysis.

In a preliminary experiment four sponges were implanted into each rat and groups of animals were ${ }_{0}^{N}$ killed 1, 2, 4, 6, and 10 days later. Three sponges. were trypsinized to liberate the cells and cell counts were performed (Ford-Hutchinson et al., 1975). The remaining sponge was fixed in neutral formalin, imbedded in paraffin, and $8 \mu \mathrm{m}$ sections stained witho haematoxylin-eosin. In a further experiment the increase in the wet weight of the sponges was? determined at various times after implantation.

In the radioactivity study, $8 \mu \mathrm{Ci} / \mathrm{kg}$ of body weight $\frac{}{\Phi}$

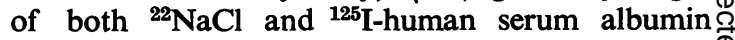
(Radiochemical Centre, Amersham, UK) was injected intravenously via the tail vein. The activities 
of each isotope in the inflammatory exudates and plasma were determined using a gamma radiation spectrometer (Ultrogamma, LKB-Wallac, Turku, Finland).

Drug-protein binding was measured using an ultrafiltration method. $1 \mathrm{ml}$ samples of plasma or inflammatory exudate were placed in membrane ultrafiltration cones with a molecular weight cut-off of 50000 (CF50A, Amicon B.V. Oosterhout (N.B.) Holland) and centrifuged at $1000 \mathrm{~g}$ for 15 minutes at room temperature. Approximately $0.5 \mathrm{ml}$ of filtrate was obtained. The concentration of drug in an aliquot of the original sample (total drug concentration) was determined by reference to a calibration curve constructed using standard solutions of drug in phosphate buffer. The concentration of drug in the filtrate was estimated by reference to a calibration curve constructed from the filtrates of a series of standard solutions in phosphate buffer. In this way the effects of nonspecific binding of the drugs to the membrane were eliminated.

Salicylate was determined fluorimetrically by the method of Öie and Frislid (1971). Naproxen was determined by a fluorimetric method developed in this laboratory (Anttila, 1976).

\section{Results}

DEVELOPMENT OF INFLAMMATORY REACTION TO IMPLANTED SPONGES

1,2 , and 3 days after implantation the sponges were easily separated from the surrounding tissue, and were covered by a thin connective tissue membrane. There was no vascularization of the sponge at this stage. On days 6 and 10 there was a progressively increasing infiltration of the sponges by connective tissue containing new capillaries. This made the sponges difficult to remove cleanly without contamination with blood and tissue. Histological examination of the sponges showed an even distribution of inflammatory cells throughout the sponges on days 1,2 , and 4 , although there were fewer cells present on day 4. At later times there were very few inflammatory cells but a dense band of connective tissue was seen to be gradually penetrating the sponges from all surfaces. On day 10 this connective tissue had penetrated to a depth of 1-2 mm, while the centres of the sponges were free of cells.

The Table shows the number of cells liberated from the sponges by trypsin treatment. On days 1 and 2 the presence of large numbers of polymorphonuclear leucocytes in addition to mononuclear cells indicated an active inflammatory reaction in the sponges. Although the polymorphonuclear cells disappeared the mononuclear inflammatory cells persisted, though in reduced numbers. On day 6
Table Sponges were collected and trypsinized at various times after implantation, and total and differential leucocyte counts performed. Results are expressed as millions of cells per sponge (means of 8 observations $\pm S E$ )

\begin{tabular}{lllll}
\hline & \multicolumn{4}{l}{ Days after implantation } \\
\cline { 2 - 5 } & 1 & 2 & 3 & 6 \\
\hline $\begin{array}{c}\text { Polymorphonuclear } \\
\text { leucocytes }\end{array}$ & $9 \cdot 8 \pm 3 \cdot 1$ & $8 \cdot 4 \pm 4 \cdot 3$ & $0 \cdot 4 \pm 0 \cdot 3$ & 0 \\
$\begin{array}{c}\text { Mononuclear } \\
\text { leucocytes }\end{array}$ & $5 \cdot 0 \pm 2 \cdot 3$ & $8 \cdot 2 \pm 3 \cdot 4$ & $7 \cdot 7 \pm 4 \cdot 2$ & $5 \cdot 7 \pm 2 \cdot 4$ \\
\hline
\end{tabular}

small numbers of polykaryons were seen containing 2 to 6 nuclei. On day 10 the capsule of connective tissue was so dense that trypsinization was not possible. Histological examination of the sponges after trypsinization indicated that although most of the inflammatory cells were removed the connective tissue capsule was unaffected by this treatment.

The wet weight of the sponges increased rapidly for the first 12 hours after implantation and remained constant thereafter (Fig. 1). The maximum weight achieved in vivo was equal to the maximum weight of water the sponges could absorb.

On the basis of the above results the 24- to 36hour period after sponge implantation was chosen as the most suitable time for further study. Both drugs and isotopes were administered 24 hours after sponge implantation and their levels in plasma and inflammatory exudate measured during the following 12 hours.

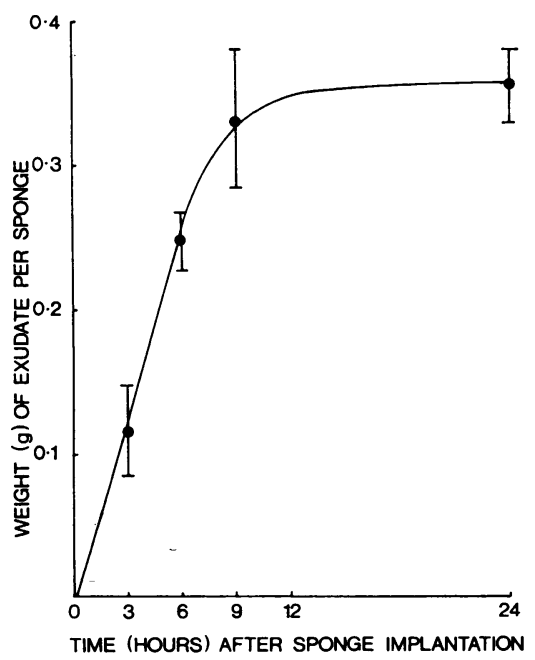

Fig. 1 Increase in the wet weight of subcutaneously implanted plastic sponges (means $\pm S E M$ of 5 observations). 


\section{RADIOACTIVITY ST UDIES}

${ }^{22} \mathrm{Na}$ penetrated very rapidly into the inflammatory exudate and took less than 3 hours to achieve equilibrium (Fig. 2). ${ }^{125} \mathrm{I}$-albumin, however, penetrated much more slowly and equilibrium was not achieved within the 12 hours of the experiment (Fig. 3).

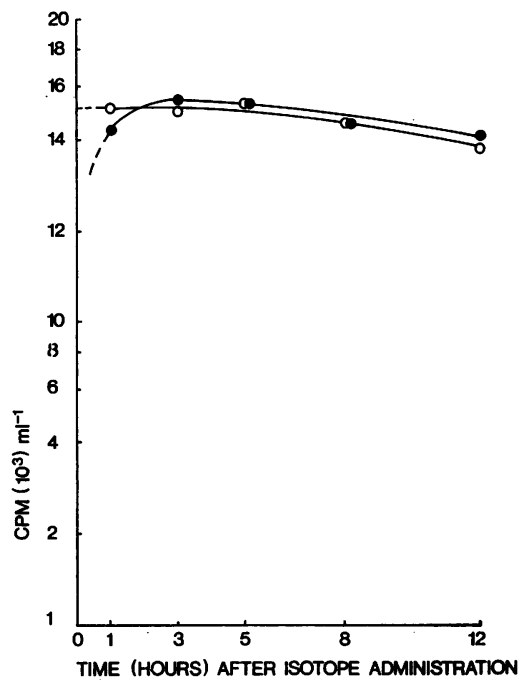

Fig. 2 Specific activity of ${ }^{22} \mathrm{Na}$ in plasma (0) and sponge fluid (๑) after intravenous injection (means of 4 observations, SEM was $<7 \%$ of the mean for all points). Sponges were implanted 24 hours before injection.

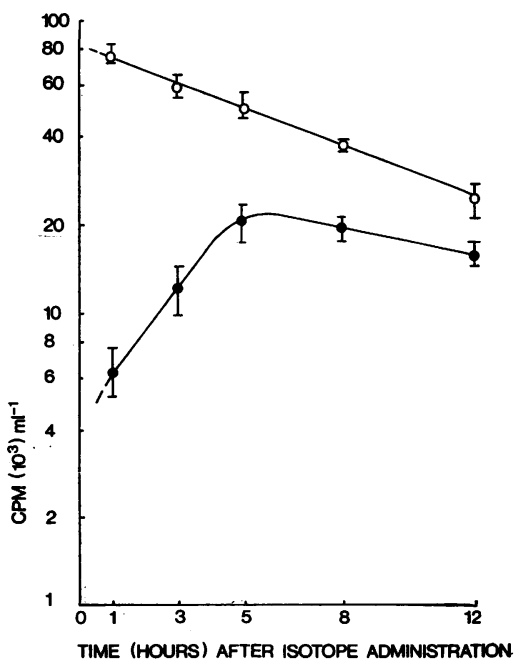

Fig. 3 Specific activity of ${ }^{125}$ I-albumin in plasma (0) and sponge fluid (๑) after intravenous injection (means $\pm S E M$ of 4 observations). Sponges were implanted 24 hours before injection.

\section{DR UG DISPOSITION}

Sodium salicylate penetrated rapidly into the inflammatory exudate, but the concentration there remained slightly $(2-15 \%)$ below plasma concentrations at all times (Fig. 4). In contrast, naproxen penetrated slowly, as indicated by the 4-hour difference between the time of maximum plasma concentration and maximum inflammatory exudate concentration. Furthermore, 8 hours and more afteres drug administration the concentration of drug in the inflammatory exudate was higher than the concen: tration in plasma (Fig. 5).

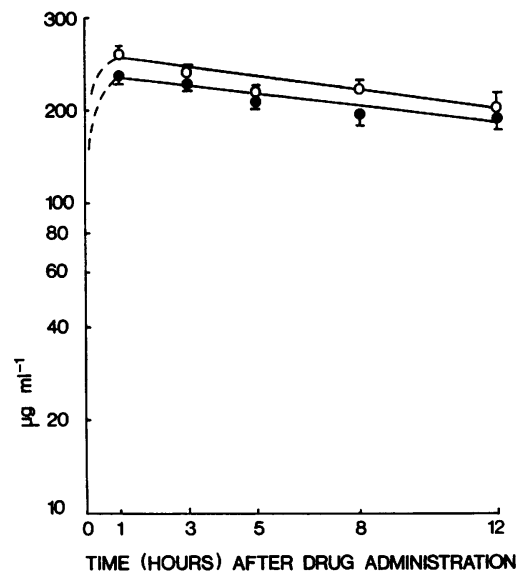

Fig. 4 Concentration of salicylate in plasma (o) and sponge fluid (०) after oral administration of $200 \mathrm{mg} / \mathrm{kg}$ sodium salicylate (means $\pm S E M$ of 4 observations). Sponges were implanted 24 hours before drug administration.

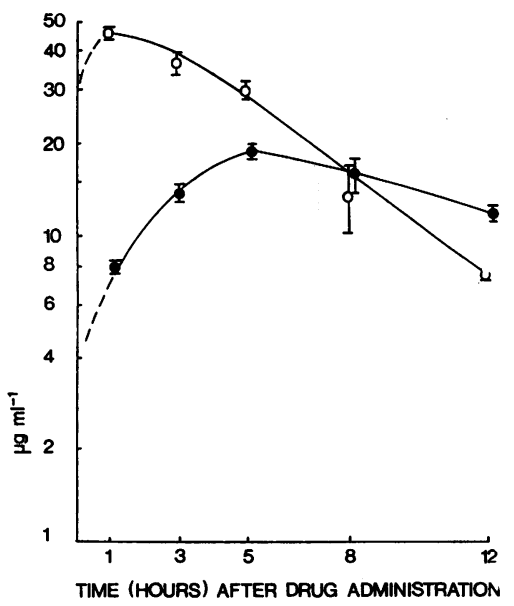

Fig. 5 Concentration of naproxen in plasma (o) and sponge exudate (๑) after oral administration of $10 \mathrm{mg} / \mathrm{kg}$ naproxen (means $\pm S E M$ of 4 observations). Sponges were implanted 24 hours before drug administration. 


\section{PROTEIN BINDING}

Inflammatory exudates from 3 to 4 rats, killed 5 hours after drug administration, were pooled in order to obtain sufficient material for determination of protein binding. The percentage of free salicylate was similar in inflammatory exudate (mean $49 \cdot 3 \pm$ $4 \cdot 5$ SEM) and plasma $(48 \cdot 8 \pm 1 \cdot 5)$. Accurate data could not be obtained for naproxen because at the dose used $(10 \mathrm{mg} / \mathrm{kg})$ the concentration of free drug was too low for accurate measurement. It was clear, however, that the percentage of free drug was less than $2.5 \%$ of the total in both plasma and inflammatory exudate.

\section{Discussion}

The presence of large numbers of polymorphonuclear leucocytes in the sponges during the first 2 days after implantation (Table) indicates that sponge implantation induces an acute inflammatory response. However, the histological evidence indicates that the inflammation is of relatively short duration and is replaced by a period of connective tissue activity. During the first 12 hours after implantation the sponges absorb fluid (Fig. 1), probably derived from both the local extravascular fluid and from extravasated plasma. Since the object of the present investigation was to study only the latter phenomenon, the 24- to 36-hour period was used. At this time the sponges are full and therefore will not act as a sink into which extravascular fluid drains, but, due to the increased vascular permeability induced by the inflammation a flux of extravasated plasma is maintained (Fig. 3).

Albumin and the extensively albumin-bound drug, naproxen, penetrated into the sponges relatively slowly. However, the plasma concentration of naproxen fell more rapidly than the concentration in inflammatory exudate, with the result that 8 hours after dosing the inflammatory exudate concentration was higher. In contrast, sodium ions and a much less extensively protein-bound drug, salicylate, penetrated rapidly and the concentration of salicylate in the inflammatory exudate never exceeded the plasma concentration. Similar data have been obtained in studies in humans of the rate of penetration of antirheumatic drugs into synovial fluid. For example, Emori et al. (1973) found that indomethacin, a drug which is extensively protein bound, penetrates into the synovial fluid of rheumatoid patients quite slowly, but because the serum concentration fell more rapidly than the synovial fluid concentration the latter was the higher of the two, 5 hours after drug administration. Rosenthal et al. (1964) showed that when a relatively stable plasma salicylic acid level is maintained in patients with rheumatoid arthritis, the total concentration in the synovial fluid is lower than the plasma concentration. However, this difference is due to the different albumin concentrations in plasma and synovial fluid, the higher plasma albumin concentration meaning that a greater proportion of the drug is protein bound in plasma and in fact the free drug concentrations are equal. The similarity between these results and the results obtained in the present rat model suggest that this model could be used to examine the disposition of potential anti-inflammatory/antirheumatic agents.

The ability of acid-inflammatory agents to bind to plasma proteins, particularly albumin, has led many authors to suggest that this property is intimately involved in their mode of action. Indeed, as pointed out by Hichins (1974) many of the methods developed for screening potential antiinflammatory agents in vitro merely measure protein binding using a variety of different indicator systems, e.g. displacement of albumin-bound tryptophan (McArthur et al., 1971), inhibition of the thermal denaturation of albumin (Mizushima, 1964), sulphydryl-disulphide interchange (Hichins, 1974), and inhibition of erythrocyte lysis (Mizushima and Sakai, 1969). More recently it has been claimed that the protein binding of these drugs together with their low $\mathrm{pKa}$ values, results in higher concentrations of drug in inflamed tissues (Graf et al., 1975).

The results of our investigation do not support this suggestion since the highly protein-bound naproxen penetrated much more slowly than the less extensively protein-bound salicylate. The similarity between the penetration of albumin into the inflammation and the penetration of naproxen suggests that naproxen penetrates largely as drug/albumin complex. It may therefore be said that drug/albumin binding inhibits the rate of penetration of drug into inflamed tissues, despite the increased permeability to plasma protein in such tissues. The higher inflammatory fluid concentration of naproxen seen 12 hours after dosing is probably due to the greater rate of metabolism and excretion of the drug in the plasma compared to drug in the inflammatory exudate (Emori et al., 1973) and cannot therefore be considered specific accumulation due to protein binding.

There are, however, a number of other possible explanations for the observation that the degree of protein binding of this class of drugs correlates with their anti-inflammatory potency. The acidic anti-inflammatory agents are potent inhibitors of prostaglandin synthetase (Flower, 1974), and prostaglandins are believed to have an important physiological role in many tissues (Horton, 1976). Therefore the significance of the protein binding of these drugs 
may be that it reduces their penetration into noninflamed tissues, thereby reducing the toxicity which would result from widespread inhibition of prostaglandin synthetase. Alternatively, the site of action of these drugs may be, at least partly, intravascular, for example on platelets, leucocytes, or vascular endothelium. In this situation albumin binding would serve to maintain a high concentration of drug at the site of action.

N.S.D. was supported by the European Fellowship Scheme of the Royal Society, London.

\section{References}

Anttila, M. (1976). Fluorimetric determination of naproxen in serum. Journal of Pharmaceutical Sciences (in press).

Emori, H. W., Champion, G. D., Bluestone, R., and Paulus, H. E. (1973). Simultaneous pharmacokinetics of indomethacin in serum and synovial fluid. Annals of the Rheumatic Diseases, 32, 433-435.

Flower, J. R. (1974). Drugs which inhibit prostaglandin biosynthesis. Pharmacological Reviews, 26, 33-67.

Ford-Hutchinson, A. W., Smith, M. J. H., Elliott, P. C. N., Bolam, J. P., Walker, J. R., Lobo, A. A., Badcock, J. K., Colledge, A. J., and Billimoria, F. J. (1975). Effects of a buman plasma fraction on leucocyte migration into inflammatory exudates. Journal of Pharmacy and Pharmacology, 27, 106-112.

Gillette, J. R. (1973). The importance of tissue distribution in pharmacokinetics. Journal of Pharmacokinetics and Biopharmacy, 1, 497-520.
Graf, P., Glatt, M., and Brune, K. (1975). Acidic nonsteroid anti-inflammatory drugs accumulating in inflamed tissues Experientia, 31, 951-953.

Hichens, M. (1974). Molecular and cellular pharmacology of the anti-inflammatory drugs: some in vitro properties related to their possible modes of action. Anti-inflammatory Agents, Vol. 2, p. 263. Ed. by R. A. Sherrer and M. WO Whitehouse. Academic Press, New York.

Horton, E. W. (1976). Prostaglandins-mediators, modulatorsD or metabolites. Journal of Pharmacy and Pharmacology 28, 389-392.

Koch-Weser, J., and Sellers, E. M. (1976). Binding of drugsto albumin. New England Journal of Medicine, 294, 311-316.

McArthur, J. N., Dawkins, P. D., and Smith, M. J. H. (1971) Displacement of L-tryptophan and dipeptides from bovine albumin in vitro and from human plasma in vivo by antio rheumatic drugs. Journal of Pharmacy and Pharmacology 23, 393-398.

Mizushima, Y. (1964). Inhibition of protein denaturation bł antirheumatic or antiphlogistic agents. Archives Inter $N$ nationales de Pharmacodynamie et de Thérapie, 149, 1-7.

Mizushima, Y., and Sakai, S. (1969). Stabilization of erythrocyte membrane by non-steroid anti-inflammatory drugs. Journal of Pharmacy and Pharmacology, 21, 327-328

Oie, S., and Frislid, K. (1971). A fluorimetric method for direct determination of plasma salicylate. Pharmaceutic Acta Helvetiae, 46, 632-636.

Rosenthal, R. K., Bayles, T. B., and Fremont-Smith, K $\vec{\bullet}$ (1964). Simultaneous salicylate concentrations in synovia fluid and plasma in rheumatoid arthritis. Arthritis and Rheumatism, 7, 103-109.

Williams, T. J., and Morley, J. (1974). Measurement of rate of extravasation of plasma protein in inflammator responses in guinea-pig skin using a continuous recording method. British Journal of Experimental Pathology, 55 1-12. 